\title{
EL TEMA DE LOS ESCONDIDOS DE LA POSGUERRA ESPAÑOLA EN LA PRODUCCIÓN TEATRAL DE ANTONIO GALA Y JUAN JOSÉ ALONSO MILLÁN
}

\author{
MARÍA ISABEL YAGÜE FERRER \\ Universidad de Zaragoza
}

\begin{abstract}
Todos, en algún momento de nuestra vida, hemos querido huir y escondernos. Y permanecer ocultos hasta que nuestros enemigos se hubieran marchado para siempre, aunque éstos se encontrasen dentro de nosotros mismos.
\end{abstract}

\section{INTRODUCCIÓN}

El teatro, expresión de realidades y miserias humanas, aborda el tema de los escondidos, con motivo de la guerra civil española de 1936, en dos obras pertenecientes a dos autores españoles de muy diferente perfil, tanto en su trayectoria personal como literaria, diferencia que nos va a permitir aproximarnos a este tema con una más amplia perspectiva. Estas piezas dramáticas son Noviembre y un poco de yerba, de Antonio Gala, cuyo protagonista, Diego, en el momento de subirse el telón, lleva viviendo en la clandestinidad veintisiete años, y Se vuelve a llevar la guerra larga, de Juan José Alonso Millán, cuyo protagonista, Benito, ha consumido, de la misma forma, treinta y cinco. Ambos, aunque de bandos bélicos contrarios, el primero del bando vencido y el segundo del vencedor, son víctimas de la guerra en idéntica medida ${ }^{1}$.

\footnotetext{
${ }^{1}$ En la vida real, los ocultos del bando nacional salieron de su escondite en 1939, los del bando republicano tuvieron que esperar más tiempo. Salían a la luz a medida que, desde el año 1945, se iban promulgando los sucesivos Indultos para extinción de responsabilidades políticas por todos los delitos cometidos con anterioridad al $1 .^{\circ}$ de abril de 1939. El indulto definitivo se decretó el 31 de marzo de 1969. Para adentrarse en el conocimiento de lo vivido por estas personas, es imprescindible la lectura de las
}

Rlit, LXIV, 128 (2002), 505-521 
Junto a ellos, aparecen en escena otras dos protagonistas: Paula y Josefina. Son sus respectivas parejas con las que conviven maritalmente desde el principio de su encerramiento. Las circunstancias les impedirán contraer matrimonio, incluso una vez recobrada su libertad.

Aunque, el protagonista común de las dos producciones dramáticas es el miedo. En Diego y Benito, el miedo a ser descubiertos y, posteriormente, fusilados ${ }^{2}$. En Paula y Josefina, el temor a que sus hombres las abandonen para buscar otro escondite en un lugar diferente, quizá con su primera familia. Los cuatro están sometidos a sus propios miedos y a los de sus parejas.

Nuestros protagonistas masculinos, tras escapar de la lucha en el frente y lograr esconderse, caen prisioneros de las personas que les protegen. A partir de ese momento, serán, irremediablemente, víctimas de una doble contienda, la bélico-social y la personal, de la que Diego no podrá librarse y Benito no querrá hacerlo ${ }^{3}$.

Los elementos comunes existentes entre las dos piezas dramáticas aquí estudiadas y los testimonios reales de hombres ocultos recogidos por escrito por Ronald Fraser, Jesús Torbado y Manuel Leguineche son, básicamente, la causa inicial de su fuga y su posterior encerramiento en lugares inaccesibles. A partir de aquí, Gala y Alonso Millán introducen otros elementos argumentales, producto de su propia creatividad literaria, que no son óbice para que, al mismo tiempo, lleven a cabo un análisis a fondo - principalmente el autor cordobés- de distintos aspectos de la sociedad española durante la etapa franquista, consecuencia derivada de la guerra

monografías de Ronald FRASER, Escondido. El calvario de Manuel Cortés (título original: In Hiding. The Ordeal of Manuel Cortés, 1972, trad. Eva Rodríguez Halffter), Valencia, Institució Alfons el Magnànim, Institució valenciana d'estudis i investigació, 1986; y Jesús ToRbado y Manuel Leguineche, Los topos, Madrid, Edit. El País-Aguilar, 1999, 3. a edic. También aporta alguna información C. B. AGESTA y otros, Libro personal '67 de recuerdos, Barcelona, Seix y Barral hnos, 1977, p. 33, art. «Han estado encerrados treinta años». Por respeto a la dignidad personal de los hombres escondidos, preferimos prescindir, en nuestra redacción, del apelativo topo, utilizado por ellos mismos, por sus evidentes connotaciones con el reino animal.

${ }^{2}$ En J. TORBADO y M. LEgUINECHE, op. cit., passim, se ofrecen múltiples testimonios de fusilamientos entre las personas que salieron acogiéndose a la firma de los distintos indultos de Francisco Franco.

${ }^{3}$ Es importante destacar, en este momento, que, por distintos motivos, el Padre de El tragaluz, de Antonio Buero Vallejo, y la protagonista femenina de la novela de Ramón José Sender, El rey y la reina, citada brevemente al final de este trabajo, recluidos en su casa por culpa de la misma guerra civil, tampoco salen a la luz pública, por internamiento en un sanatorio psiquiátrico del primero y por muerte en su domicilio de la segunda. A los encerrados nacidos de la creación literaria les está vedada la libertad. 
civil, como el racionamiento de los alimentos, el aislamiento de España, la censura o la emigración ${ }^{4}$.

\section{Noviembre y un POCO DE YeRba, De ANTONio Gala}

Este drama, encuadrado en el teatro realista crítico por su tema y sus características formales, se estrenó el 14 de diciembre de 1967, en el Teatro Arlequín de Madrid, bajo la dirección de Enrique Diosdado. A pesar de que el tema abordado estaba de plena actualidad, tras el indulto del año anterior y subsiguiente salida de escondidos, fue retirado del cartel pocos días después, por su escasa comercialidad.

Este fracaso pudo deberse a que tanto a la crítica como al público les pareció la pieza falta de acción, que no ahondaba en la psicología de los personajes y que finalizaba con un trágico desenlace innecesario. Advirtieron, igualmente, el excesivo verbalismo de sus diálogos, interrumpidos constantemente por las cancioncillas y rezos de la madre de la protagonista, psíquicamente enferma. Los críticos añadieron que el tema de los escondidos era tratado con dureza y recordaba al espectador que los vencidos no se habían sabido integrar plenamente en la sociedad española y que muchos de ellos estaban pagando todavía las duras consecuencias de su alineación, durante la contienda, a favor de la República ${ }^{5}$. Nada señalaron sobre la sordidez de la escenografía ${ }^{6}$ y de los diálogos, que resonarían con

\footnotetext{
${ }^{4}$ Como es sobradamente conocido, miles de ciudadanos españoles tuvieron que emigrar como consecuencia de la guerra civil. Recogemos aquí la opinión de uno de los escondidos, Manuel Cortés, alcalde de Mijas en 1936, treinta años oculto, sobre este sangrante aspecto de la existencia de tantas personas: «Pero yo me pregunto, ¿Es un triunfo económico de un país tener que importar turistas y exportar trabajadores a otras naciones de Europa para poder vivir? ¿Es un triunfo en un país que tiene tradición de crianza de ganado tener que importar carne? ¿O que, menos las grandes fincas capitalistas, se abandone la tierra y los campesinos salgan a ponerse de jornaleros o a emigrar? Yo creo que no. Vivir de las divisas que trae el turismo por un lado, y que mandan los trabajadores españoles de fuera por el otro, eso en mi opinión no puede ser fundamento de una economía firme», en R. FRASER, op. cit., p. 224. Para conocer más profundamente cuáles fueron las causas económicas que produjeron la marcha de tantos españoles fuera de nuestra Península, véase José Antonio BIESCAS FERRER y Manuel TUÑón DE LARA, España bajo la dictadura franquista. (1939-1975), Tomo X de Historia de España, dirigida por Manuel Tuñón de Lara, Barcelona, Edit. Labor, 1980, cap. Estructura y coyunturas económicas, pp. 21-167.

5 En El espectador y la crítica, de 14 de diciembre de 1967, pp. 174-179 y en Antonio GALA, El caracol en el espejo. El sol en el hormiguero y Noviembre y un poco de yerba, Madrid, Taurus, colección El mirlo Blanco, 1970, Introducción, pp. 9-83, se recogen estas opiniones de la crítica tras su estreno.

${ }^{6}$ Recogida fotográficamente en la revista Primer Acto, n. ${ }^{\circ}$ 94, marzo de 1968, p. 19. Es clara representación simbólica de la España cerrada. El pequeño cubículo produce un
} 
toda seguridad en los oídos de los espectadores de entonces más acostumbrados a las palabras almibaradas de obras como Prohibido suicidarse en primavera (1965), de Alejandro Casona o El baño de las ninfas (1966), de Joaquín Calvo-Sotelo.

Noviembre y un poco de yerba gira alrededor de un hombre y una mujer en una situación límite. Viven en la incertidumbre de no saber cuál va a ser su futuro cuando Diego, el protagonista, pueda salir definitivamente de su agujero. Su angustia va en progresión ascendente a medida que ven cada vez más próxima su salida, que el autor hará coincidir con el final de la pieza dramática.

Las características de los protagonistas del tercer estreno teatral de Antonio Gala son las siguientes:

- La actitud insolente y، despectiva de Paula hacia los demás que le mueve a plagar su discurso de insultos y palabras poco oportunas. A esto se suma su predisposición al uso continuo de la mentira, sin medir las consecuencias que de él se derivan.

- El carácter de tipo dependiente ${ }^{7}$ de Diego, con manifestaciones de infantilismo y de indolencia que exacerban al público ya que, además, no ve en él un hombre que se crezca ante las dificultades y que agudice su ingenio para ayudarse a sí mismo y a los que le rodean a salir adelante. Diego no tiene tampoco el gesto de reconocer algo positivo en su vida, como no haber muerto en la guerra o el hecho de haber podido formar una familia.

fuerte efecto claustrofóbico dentro de un sótano en el que nunca entra aire fresco y donde han convivido, en tiempos pasados, hasta seis personas. Más detalles en Victoria Robertson, El teatro de Antonio Gala: Un retrato de España, Madrid, Edit. Pliegos, 1990, ap. Noviembre y un poco de yerba, pp. 64-73.

${ }^{7}$ Los rasgos más destacados de la persona de carácter dependiente son: incapacidad para subsistir sola, deseo de ser guiada y protegida y dificultad para expresar emociones y sentimientos. Espera de la persona de la que depende todo en la vida, en vez de intentar conseguirlo por medio de sus propias acciones. También, es sumisa y complaciente, tímida, aislada, arisca y descarada, inhibida en la investigación y experimentación, temerosa de iniciar actividades o de actuar de forma independiente. La causa de este carácter se debe buscar en una madre excesivamente protectora en la época de la niñez. Es muy frecuente en hijos únicos. Para más detalles sobre estas características, véase Theodore MILlON y George S. EVERLY, Jr, La personalidad y sus trastornos (tít. orig. Personality and its Disorders: A Biosocial Learning Approach, 1985, trd. Josep Treserra i Torres), prólogo de Manuel Valdés, Barcelona, Ediciones Martínez Roca, 1994, parte III. Trastornos de la personalidad por dependencia, pp. 75-105. La bibliografía más reciente sobre las alteraciones de este carácter se puede consultar en Lisa EKSELIUS y Martin ERIKSON, «Personality Disorders and Major Depression in Patiens with Somatoform Pain Disorders and Medical Illnesses in Relation to Age at Onset of Work Disability», The European Journal of Psychiatry, vol. 10, n. ${ }^{\circ}$ 1, January/March, Zaragoza, 1996, pp. 35-43. 
- La locura de la Madre, ocasionada por la muerte de su amado. Ella es la antítesis de lo que debe ser una madre para una hija: no ha ayudado nunca a Paula a soportar las cargas y los duros trances de su vida con su consejo, su consuelo o su trabajo. Padece obsesión con un hombre al que amó después de la muerte de su esposo y que le lleva a describir, con realismo y de modo reiterativo, unas relaciones sexuales que nunca existieron.

El modo de comportamiento de Paula está causado por las desgracias que le ha ocasionado la guerra civil: la enfermedad mental de su progenitora, por la que se ve obligada a actuar como la madre de su propia madre, y la marcha de sus tres hijos de los que no tiene noticia alguna desde que emigraron al extranjero. También, de consecuencias desastrosas para su vida ha sido la pérdida de su trabajo en la cantina de la estación de su pueblo donde, antes de estallar la guerra, disfrutaba de una buena clientela en un buen ambiente. En la actualidad, trabaja en la cantina del apeadero, en las afueras del pueblo, y en ella atiende a muy pocos viajeros. En un futuro inmediato, resultará dolorosa la marcha de su compañero, que su Madre, vidente de profesión antes de la guerra, le predice con sus canciones.

El sentimiento de frustración continuo se exterioriza en Paula por medio de una actitud displicente ${ }^{8}$ dirigida sobre todo hacia Diego; por ello no sorprende que, al final de la pieza dramática, Diego le confiese: «-Te he aborrecido siempre.» (Noviembre..., $178^{9}$ ). Paula, con la fuerza de su personalidad, ofende la dignidad de Diego en la faceta más importante de la vida de un hombre, la de su trabajo, cuando desprecia el único producto que él es capaz de elaborar con sus manos durante veintisiete años: unos carritos de madera para el juego de los niños.

PAUlA. Al caracho los carritos, desgraciao. ¡Entérate de una vez! ¡Los tiro! Hace ya meses que los vengo tirando en cuanto salgo arriba. Nadie los quiere ya. En el pueblo están hartos de carritos. Todos los niños están hartos de tus estúpidos carritos ${ }^{10}$ (Noviembre..., 147).

${ }^{8}$ Ésta es, también, la principal característica de Hortensia de la producción teatral galiana Los buenos días perdidos (1972), las causas que la producen se hallan analizadas en la Introducción de Andrés Amorós a: Antonio GALA, Los buenos días perdidos. Anillos para una dama, Madrid, Clásicos Castalia, 1988, pp. 33-66.

9 Antonio Gala, Noviembre y un poco de yerba. Petra Regalada, edic. Phyllis Zatlin Boring, Madrid, Cátedra, 5. ${ }^{a}$ edic., 1993. El resto de las citas de esta obra corresponde a esta edición.

${ }^{10}$ Sobre el recurso lingüístico de las palabras injuriosas en la dramaturgia de Gala, véase Fausto DíAZ PADILlA, El habla coloquial en el teatro de Antonio Gala, Oviedo, Servicio de publicaciones de la Universidad de Oviedo, 1985, cap. 2.b. Los insultos, pp. 52-67. En Noviembre ..., la variedad y el número de insultos que en ella se profieren es superior a los que se recogen en otras piezas del mismo autor, si exceptuamos a 
En toda pareja siempre hay un miembro que domina, de manera más o menos sutil, y otro que se deja dominar. Paula utiliza todos los recursos de que es capaz durante veintisiete años para tener sometido a su compañero. Su sometimiento es extremo, paralelo a su extrema debilidad interior. El recurso más efectivo, a todas luces, es el de la mentira y la ocultación, con la única finalidad de que Diego no desee nunca salir de su cuartuchovivienda ${ }^{11}$ para buscar otro refugio donde esperar su definitiva salida al exterior, una vez desaparecidos todos los peligros de encarcelamiento o de pena de muerte que acechan a un perdedor de una guerra civil.

En repetidas ocasiones, a lo largo de toda la pieza, a petición de Diego, ella le describe cómo es el mundo exterior y carga las tintas negras todo lo posible para que no le resulte tentadora la idea de salir a verlo:

PAULA. ... No hay nada arriba: polvo, piedras y cuatro matas secas.

DIEGO. ¿Y el aire?

Paula. (Como si le hablara a un niño.) El aire es malísimo. Te da y te salen granos, llagas o te da un paralís ... Hay que apartarse de los hormigueros, de los barrancos, de los cenagales. Todo eso trae muy mala suerte... Antes de irse al campo, conviene echarse entre pecho y espalda tres tragos de aguardiente. Así (Noviembre..., 134).

Mas Paula tiene un descuido que le costará extraordinariamente caro cuando, para celebrar el aniversario de su vida en común, regala a Diego un transistor. Pronto se dará cuenta del peligro de esta intromisión del mundo exterior en su casa e impide a Diego, en repetidas ocasiones, que lo escuche: «Paula.- ¿Para qué habré yo traído eso? Ya hemos metido al enemigo en casa. (Paula desconecta la radio.)» (Noviembre..., 156). Esta desconexión es una forma más de la castración intelectual a que somete a Diego como forma de dominación y que ella ejecuta sin ningún prejuicio ni reserva moral ${ }^{12}$.

La vieja señorita del Paraíso (1980). El autor cordobés hace uso, en boca de Paula, de términos tan altisonantes como zorrón desorejao (p. 172), que alterna con otros más eufemísticos como ¡Hijo de la gran no se qué! (p. 151) o pájaro negro (p. 126) (en él se asocian las ideas de pájaro de mal agüero y de cuervo, y se refiere al sacerdote que comunica la mala noticia de la muerte del hombre que ama la Madre de Paula), junto a otros muy sonoros, propios del lenguaje andaluz, como trampantojo (p. 141), so zanguango (p. 153), papandujo (p. 11), etc., y el extraño turmix salamanquesa (p. 115), referido a la guerra.

${ }^{11}$ Símbolo de España. Véase V. RoberTson, op. cit., pp. 26-35.

${ }_{12}$ Este control a que es sometido Diego es paralelo al desarrollado por las autoridades del Ministerio del Interior del gobierno franquista, que contaban, como es sabido, con la Sección de Censura de Libros, el Departamento de Teatro y Cinematografía y la Sección de Información y Censura, para calibrar la cantidad o la proporción de información y de conocimientos culturales que debía recibir la sociedad española. Para adentrarse en este tema se debe leer la monografía de Manuel L. ABELLÁn, Censura y creación literaria en España (1936-1976), Barcelona, Ediciones Península, 1980. Para una des- 
Como consecuencia directa de esta dura opresión, casi rayana en esclavitud, Diego se rebela y opta por escuchar la radio a escondidas, por la noche o cuando ella está trabajando en la cantina. Esta desobediencia, que es aparentemente inconsciente, ocasionará su caída mortal a partir del momento en que sintoniza la emisión de la lectura de la concesión del Indulto para extinción de responsabilidades políticas:

PAUlA. ... ¿Dónde has puesto la radio? ... Es mía. Dámela. Si no puede ser de los dos, es sólo mía.

DIEGo. No, es mía nada más. (Una breve lucha por la radio. Paula, empujada, cae al suelo. Está extrañada sobre todo.)

DIEGo. ... Anoche la puse un poco. Sólo un poco. Mientras tú dormías. Muy bajito. Ni siquiera te diste cuenta ... Decía que todos los que habíamos estado en la guerra podíamos salir arriba, volver, ¿te enteras?... (Noviembre..., 169).

Paula no podía sospechar que, con su regalo, con el que pretendía «sobornar» a su pareja para que continuara dejándose dominar, los acontecimientos iban a desencadenarse de manera tan precipitada e irreversible. Si para ella la radio toma el carácter de una intrusa, para Diego se convierte en la redentora que le va a infundir valor para salir fuera de su escondite y abandonar su vida presente de atonía total ${ }^{13}$.

Paula, asustada e insegura de sí misma, ante la posibilidad de perder para siempre a Diego, una vez que había determinado salir y presentarse a las autoridades, decide, de nuevo, hacer uso de la mentira y le dice a Diego que van a tener un hijo. Con esta falsedad, la de más envergadura de las concebidas por nuestra protagonista, quiere que Diego sienta que hay algo que le ata a ella, algo que le empuja a regresar a su lado e iniciar juntos una nueva vida en libertad ${ }^{14}$.

cripción exhaustiva del ambiente cultural general de España, en el período histórico del franquismo, puede consultarse: J. A. BIESCAS y M. TUÑón, op. cit., Tercera parte: Cultura e Ideología, págs. 435-523. Nuestra protagonista dosifica en grado extremo la información que pueda llegar a la bodega desde el mundo exterior, incluso ella misma calla cuantos hechos conoce de la realidad social de dentro y fuera de su pueblo. En la bibliografía consultada sobre los escondidos históricos se describe de qué medios disponían, familiares y extrafamiliares, para estar enterados de lo que ocurría, en España, en el terreno social y político.

${ }^{13}$ En otras piezas de teatro de Gala, también hace su aparición un redentor que cambia el rumbo de la vida de algunos de los personajes con los que comparte el escenario. En este papel tenemos a Lorenzo de Los buenos días perdidos, Dimas de La vieja señorita del Paraíso y Mario de Petra Regalada (1980). Ellos van a permitir que Consuelo, Adelaida y Petra, respectivamente, recobren tantas esperanzas perdidas.

${ }^{14} \mathrm{El}$ niño que va a nacer, que infunde esperanzas a los protagonistas de que van a poder salir de su pozo, de su cárcel, aparece, también, así utilizado, en las últimas escenas de Los verdes campos del Edén (1963) y de Los buenos días perdidos, ambas, piezas de Gala. A este recurso acude Buero Vallejo, con este mismo sentido, en Aventura en lo gris (1963) y El tragaluz (1967). Más detalles en Mariano de PACO, De re bueriana (Sobre el autor y las obras), Murcia, Secretariado de Publicaciones de la Universidad de Murcia, 1994, pp. 67-89. 
Esta buena nueva tiene unos efectos positivos inmediatos, pues, nada más saber que va a ser padre, Diego afirma: «Un hijo ... que va a nacer al sol... Le enseñaré a subir a las ramas más altas ...A coger nidos con mucho cuidado ... Por él, voy en busca de mí. Quiero ser yo otra vez, resucitar.» (Noviembre..., 175). No se cuestiona esta paternidad, ni siente curiosidad por conocer si la edad y las condiciones físicas o psicológicas de la embarazada son, en ese momento, las idóneas. No quiere introducirse en los vericuetos del tema de la maternidad considerado por él exclusivo del mundo femenino.

Antonio Gala, en la completa descripción de la personalidad de la protagonista de Noviembre y un poco de yerba llevada a cabo, le confiere unas señas de identidad tradicionalmente asociadas al hombre y que, por lo tanto, la masculinizan:

- Recae sobre ella la responsabilidad de la dirección de su familia.

- Asume totalmente la carga del mantenimiento económico de la misma.

- Impone sus puntos de vista acerca de los distintos aspectos de la vida.

- Decide siempre sobre el futuro de los que le rodean y determina su destino final.

- No expresa sus sentimientos amorosos a Diego de manera sincera y abierta ${ }^{15}$.

- Y, por último, sale fuera de casa para desempeñar sus obligaciones laborales ${ }^{16}$.

Paula, mujer de carácter independiente, necesita que los demás dependan de ella. Esta mujer autosuficiente, con las características antedichas, que domina la voluntad de Diego y anula su libertad, cuenta, entre otros,

15 Como observamos le sucede, también, a Micaela de La vieja señorita del Paraíso:

MiCAELA.-No, señora. No consintió nunca en decir que me amaba. Por eso yo ahora veo a las parejas y me muero de pena. Porque yo tampoco se lo dije a él jamás: tuve tanto que hacer. / ADELAIDA.-Pero tú lo querías. / MiCAELA._ ¿Yo? Faltaría otra cosa. Pero, vamos, que así, pararme y mirarle y decirle: «Juan, te amo», eso nunca. (A. GALA, La vieja señorita del Paraíso, Madrid, Ediciones MK, 1981, p. 21).

16 Esta forma de comportamiento es masculinizante en la época histórica en que se representó este drama, principalmente desde el punto de vista de las espectadoras pertenecientes a la burguesía que asistieran al estreno. La Sección Femenina de la F.E.T. y de las J.O.N.S. y la Iglesia Católica, con el total respaldo del Régimen, hicieron causa común en pro de que las mujeres casadas de la clase media permanecieran en el hogar al cuidado de la familia y dejaran a sus esposos que asumieran el resto de las responsabilidades. En las clases bajas y en el medio rural este fenómeno no tuvo apenas incidencia por razones de subsistencia. Véase Bonnie S. ANDERSON y Judith P. ZINSSER, Historia de las mujeres: Una Historia propia (tít. orig. A History of Their Own, trad. Teresa Camprodón, 1988), Vol. I, Barcelona, Editorial Crítica, 1991, pp. 144-176. 
con dos precedentes teatrales: Bernarda, protagonista de la obra lorquiana La casa de Bernarda Alba (1945) ${ }^{17}$, y Gorgo de El Adefesio (1944) de Rafael Alberti ${ }^{18}$.

Paula (de Noviembre...) se muestra como una mujer sin sinuosidades en su carácter, sin caras ocultas. Diego, por el contrario, se mueve dentro de una ambigüedad que el autor mantiene desde el principio hasta el final. Nuestro protagonista se ha creado un mundo propio que le ayuda a seguir viviendo y en el que sólo él tiene cabida.

Este personaje juega un doble papel que ocasiona en el espectador duda acerca de si se comporta de este modo por amor a Paula, porque cree que así ella es más feliz y se siente más confiada. Pero la frase que pronuncia con resentimiento, casi al final de la segunda Parte: «-Te he aborrecido siempre.» (178), sume al público en un gran desconcierto, pues patentiza que él se ha dejado manipular a sabiendas, por puro egoísmo. Esa obediencia ciega, esa bondad, ese conformismo por parte de él, ese sufrir juntos el abandono de sus hijos, han sido los medios que le han servido para que Paula ejerciera gustosa el papel de «dominadora» y tomara ella sola las riendas del hogar y las responsabilidades de la pareja. Nada ha dejado a la improvisación.

Antes de la caída definitiva del telón, Diego, que hasta ahora había hecho fuerza de su debilidad, es castigado con la muerte por un triple motivo: por su falta de amor hacia Paula - penalización que es una constante, por lo demás, en la producción teatral galiana-, por ese doble juego en su trato con los demás, originado por su egoísmo, como ya hemos señalado y, por último, por su falta de fidelidad, pues parece evidente que, una vez en libertad, ya no hubiera vuelto junto a la familia que había formado hace veintisiete años. De manera contundente contesta a la petición

${ }^{17}$ La mujer es la protagonista por antonomasia del teatro de García Lorca y de Gala. Véanse los estudios de Brenda FrAZIER, La mujer en el teatro de Federico García Lorca, Madrid, Playor, 1973; Ana María PAdilla MANGAS, Tipología en la obra dramática de Antonio Gala, Córdoba, Public. Excma. Diputación Provincial y Universidad de Córdoba, 1985; y José Romera CASTILLO, «Tres dramaturgos: Arrabal, Nieva y Gala», Historia y Crítica de la literatura española, 8/1, Época Contemporánea (1939-1975), primer suplemento, por Santos Sanz Villanueva, Barcelona, Edit. Crítica, 1999, pp. 559-604.

${ }_{18}$ Ambas, únicas que ejercen el poder en sus respectivos gineceos, son el prototipo de mujeres intolerantes y represoras que provocan, de manera inexorable, la destrucción y la muerte: Bernarda induce al suicidio a su hija Adela, que había deshonrado a la familia por sus relaciones con Pepe el Romano y por el hijo que esperaba de él. La cacique doña Gorgo causa el suicidio de su sobrina Altea la Encerrada, recluida en casa para evitar la aberración de unas relaciones incestuosas. Bernarda, para reforzar su imagen masculina como dueña absoluta de su casa, paradigma de recinto claustrofóbico asfixiante, lleva siempre consigo su bastón con el que golpea el suelo cuando da órdenes. Doña Gorgo, por su parte, aparece sobre el escenario con bastón y con la barba que conserva de su hermano que se coloca, como atributo externo masculino por excelencia, siempre que quiere insistir en que sólo sobre ella recae la autoridad de toda la familia. 
de Paula de que permanezca con ella después de presentarse a las autoridades:

PAUla. Quédate. Nunca volveré a encontrar a nadie como tú.

DiEgo. A nadie que dependa tanto de ti ... A nadie que te necesite más. A nadie de quien tú puedas ser la sed y el vaso de agua. ¿No es eso? (Noviembre..., 178).

En la última escena de la pieza, en medio de una gran tensión, después de que Diego le confiesa que la aborrece, ella reconoce su fracaso definitivo $\mathrm{y}$, con gran dolor, le dice:

Paula. ... Yo soy lo único que tienes, ¿a que sí?

DIEGO. Sí.

Paula. Ya no podemos seguir viviendo en este sitio. Hemos dicho demasiadas cosas: lá verdad. No sería posible volver a empezar ... Cuando tú te acercaras, yo te vería como ahora, diciendo lo que has dicho. Es necesario cambiar la madriguera. Vete. Aprovecha tu oportunidad (Noviembre..., 179).

Paula renuncia a él, acepta la realidad y le ayuda con entereza a salir del sótano, pues comprende que, una vez dicha toda la verdad, no hay posibilidad de dar marcha atrás. Durante su primera salida al exterior, Diego debe pasar distintas pruebas premonitorias del fracaso definitivo: No puede ver a causa de los fuertes rayos del sol ${ }^{19}$, no puede andar y, además, sufre tres caídas sobre las piedras del camino, como Jesús antes de su muerte. Después, intenta, por segunda vez, subir arriba, pero la responsabilidad de hacer frente a una nueva vida le pesa demasiado y no es capaz de cargar con ella y ascender, como Sísifo, por su montaña particular. Con la ayuda del amor salvador lo hubiera conseguido, pero Diego no ama a Paula y debe morir en el interior del sótano ${ }^{20}$. La muerte de Diego produce en Paula el mismo género de locura que la padecida por su Madre, tras la muerte de Dionisio: la pieza dramática concluye con la repetición de Paula de las mismas palabras que enuncia la anciana en varias ocasiones,

${ }^{19}$ Tal como les sucedió a los escondidos de la vida real. En la recreación literaria de uno de estos casos reales, llevada a cabo por Francisco AYALA, en el relato «La vida por la opinión», incluido en La cabeza del cordero, el escondido Felipe afirma: «Los primeros días no podía yo ponerme al sol, me dolían los ojos, estaba deslumbrado, no veía, tuve que usar gafas verdes; y también mi cara estaba verde como las acelgas, de tantísimos años de oscuridad», texto recogido en Narrativa completa, Madrid, Alianza Editorial, 1993, pp. 580-588.

${ }^{20}$ C. HARRIS, op. cit., p. 150, afirma que Diego, por su falta de libertad, no puede ser él mismo. Como consecuencia de ello, no puede amar a Paula, ni es capaz de expresar ideas propias, por lo que siempre cita literalmente la Imitación de Cristo del místico alemán Tomás de Kempis y la cartilla de las primeras letras con que aprendieron a leer sus hijos. 
en momentos de verdadera demencia (pp. 177 y 180). Esta locura será el refugio que le permitirá soportar su nueva vida en soledad.

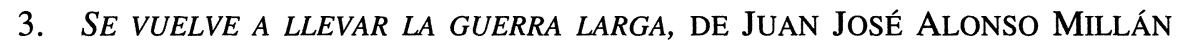

Juan José Alonso Millán, autor prolífico, estrena en 1974, en el Teatro Jacinto Benavente, la comedia Se vuelve a llevar la guerra larga dirigida por él mismo ${ }^{21}$. Aborda, desde ángulos diferentes, el mismo tema de los hombres escondidos tras la guerra civil con la particularidad de que su protagonista, que procede del bando de los vencedores, una vez recuperada la tan anhelada libertad, se ve abrumado por los cambios en todos los órdenes que descubre en su salida al exterior y decide regresar a la paz de su casa, un chalet de una zona residencial de Madrid, para no salir de ella nunca más.

Se vuelve a llevar la guerra larga es una comedia de diálogo ágil unido a una acción llena de sorpresas continuas que logran mantener la atención del espectador despierta, durante los dos actos de que consta la pieza. Pero el tema, de nuevo, no gustó.

No agradó al público ver, en el juego cómico de Alonso Millán, un hombre bueno e inteligente, dominado por los ardides de una mujer, aterrorizado por los continuos registros de los milicianos y asustado, en su primera salida a la calle, por los peligros del progreso aun cuando fuera guiado por un sacerdote amigo. Además, renuncia al prestigio y a la fama porque prefiere, antes de la caída del telón final, suspender su reputada carrera pictórica y vivir recluido para siempre en su hogar al lado de la mujer que ama.

Benito, el hombre del que hablamos, tiene un carácter sin dobleces ni recovecos. A diferencia de Diego de Gala, no guarda rencores contra sí mismo ni contra nadie por haber llegado a la situación en que se encuentra. Acepta como algo normal que las tropas nacionales, a lo largo de treinta y cinco años, hayan dado quince vueltas alrededor de España - venciendo en repetidas ocasiones en la Batalla del Ebro- a la espera de que sus mandos, hijos de los que iniciaron la Cruzada, encuentren, tras varios intentos fracasados, el momento más idóneo para liberar Madrid y, por consiguiente, para liberarlo a él.

Esta pieza cómica tiene un precedente en la obra de Víctor Ruiz Iriarte, Un paraguas bajo la lluvia, estrenada en 1965. De inferior calidad literaria, sin embargo, su contenido está más acorde con la realidad histórica: Adolfo, de su misma ideología, sale a la calle, una vez concluido el con-

\footnotetext{
${ }^{21}$ Según El espectador y la crítica, de 26 de febrero de 1974, pp. 31-37, la obra fue bien acogida por la crítica.
} 
flicto civil en 1939 - después de vivir tres años oculto en casa de su novia Florita-, pero, sobre todo, sale una vez que ha jurado a su novia casarse inmediatamente con ella.

En Se vuelve a llevar la guerra larga, Josefina, soltera de guerra como Paula de la pieza de Antonio Gala, no está tan segura como la protagonista de la comedia de Ruiz Iriarte de los sentimientos de su amado, y, en consecuencia, no se atreve a comunicarle que la guerra ha terminado.

A pesar de que los sentimientos de Benito son sinceros desde el primer día que le declara su amor, Josefina, por falta de confianza en sí misma teme que su compañero le abandone algún día para siempre por lo que se ve obligada a recurrir a las más disparatadas argucias con el fin de retenerle a su lado ${ }^{22}$; lo hace sin ofender en ningún momento la dignidad y la hombría de Benito, sin pretender la dominación por la dominación. Una diferencia fundamental con respecto a la obra de Gala es que Benito y Josefina se profesan un gran amor mutuo.

A la hora de la puesta en práctica de sus artimañas, Josefina aparece sobre el escenario como la directora de una película de acción de la que es, también, la guionista ${ }^{23}$. Dirige, con la desenvoltura que da la experiencia de treinta y cinco años de profesión, a Benito, el protagonista, y a los personajes secundarios: Venancia, la criada, D. Justo, el marchante, así como a los extras Julián, Antonio, Pedro y Elías que representan el papel de milicianos de la FAI. Dispone con eficacia los efectos especiales para simular los discursos y los partes de guerra de la radio, así como los ruidos de sirenas y bombardeos.

En estas escenas, preparadas para provocar la hilaridad del espectador y el miedo de Benito, vemos a los jóvenes extras simulando un registro:

${ }^{22}$ A diferencia de Paula de Noviembre..., Josefina no trabaja fuera de casa ni es la única en llevar las riendas de la familia. Observa un comportamiento, ante las circunstancias de la vida que le ha tocado vivir, más inteligente que aquélla porque, por ejemplo, no tiene hijos y, así, evita las críticas siempre aceradas de la sociedad dirigidas a una madre soltera. Felipe, de la obra de Ayala ya citada, es el protagonista del único caso que conocemos, tanto en lo literario como en la vida real, de un escondido que sale a la luz antes de lo debido con la única finalidad de evitar que su esposa sufriera las críticas y vejaciones que el ser madre soltera le hubiera supuesto.

${ }^{23}$ En la comedia cinematográfica de Fernando Fernán Gómez, estrenada en 1986, Mambrú se fue a la guerra, la última producción artística sobre el atrayente tema que nos ocupa, es la familia de Emiliano, el protagonista, la que acude a todo tipo de recursos para que, tras el fallecimiento de Franco, vuelva aquél de nuevo a la cueva, situada tras la pila del lavadero, en la que ha vivido encerrado durante cuarenta años, para que su esposa Florentina pueda cobrar su pensión de viuda de guerra. Esta exigencia inmoral queda expuesta al inicio de la película, el resto no contiene más que gritos y discusiones desaforadas que hacen que Emiliano sólo se entienda con su nieto Manolín, papel interpretado por Jorge Sanz, único que comprende el derecho de su abuelo a salir del escondite. 
JULIÁN. Salud. ... Estamos aquí por una denuncia.

JOSEFINA. Debe tratarse de una equivocación.

JULIÁN. Seguro. Pero prepárate como encontremos en esta casa al fascista que andamos buscando.

JOSEFINA. ¡Vamos, vamos! ... Te juro por Dolores Ibarruri, que si yo tuviera un fascista aquí sería únicamente para darle tormento.

JULIÁn. $\quad$.... Si quieres un recibo de esto que nos llevamos, vete mañana a la checa de Fomento.

ANTONIO. ¡Y mucho cuidado! ¡Te vigilamos! ... ¡Salud! ... ¡Viva Stalin! (Se vuelve..., $10-11^{24}$ )

El éxito de Josefina es absoluto, pues el signo característico por excelencia de Benito es el miedo. Éste hace de él un hombre con carácter de tipo dependiente, sin el cariz patológico de Diego, pero con una excesiva necesidad de protección, que Josefina. le proporciona sin dudarlo. Si bien es cierto que su miedo le acompaña siempre, sus facultades para el amor y el trabajo no se ven disminuidas a pesar de su situación. Benito es totalmente consciente de que vive dominado por el miedo, el mismo que él utiliza, a su vez, como modo de inspiración para pintar sus cuadros: «BENITO.-Son unas abstracciones, nacidas como siempre del miedo.» (Se vuelve..., 13). Las creaciones de Benito son de tal calidad que su marchante - de existencia desconocida para el artista - afirma:

JUSTO. El «Guernica» de Picasso resulta un cuadro cursi al lado de esta maravilla. Se palpa el terror telúrico. ... Hasta los sociólogos italianos han estudiado el caso de Bengil ... porque con su fantasía o sin ella, Bengil [Benito Gil] seguirá ganando las primeras medallas allí donde concurra. ... Se han escrito libros sobre sus telas, pero para todos la personalidad del genio es un misterio ${ }^{25}$ (Se vuelve..., 30-31).

El terror que invadía a Benito siempre que los milicianos registraban su casa se ve superado, desde el final de la primera Parte, por el que siente después de convencerse de que la guerra ha concluido hace treinta y dos años:

\footnotetext{
${ }^{24}$ Juan J. Alonso MiLlán, Se vuelve a llevar la guerra larga, Madrid, Escelicer, Colección Teatro, 769, 1974. El resto de las citas de esta obra corresponde a esta edición.

${ }^{25}$ La categoría del trabajo desarrollado por Benito tiene un cierto paralelo con la del escondido de la vida real Saturnino de Lucas que dedicó la mayor parte de sus treinta y cuatro años de vida oculta a escribir libros y tratados, que no pudo obviamente publicar, entre ellos, un diccionario políglota. Era entendido en leyes y fue un representante muy competente de varias empresas de productos múltiples que distribuía personalmente su hermano, entre sus clientes de la provincia de Segovia y limítrofes. Además de ser agente de seguros, fabricaba redes de pesca y las mejores pelotas para jugar al frontón de toda España. Más detalles en J. TORBADO y M. LEGUINECHE, op. cit., pp. 151-241.
} 
BENITO. No, Josefina. Ahora que sé que ya ha terminado la guerra, y lo que hay ahí fuera, tengo mucho más miedo que antes (74). ...Antes tenía miedo a algo que conocía ...Pero, ahora tengo otra clase de miedo. Miedo a enfrentarme a una nueva vida que me gusta muy poco (Se vuelve..., 75).

Como es sabido, el miedo provoca el deseo de huir por los más diversos motivos. Y Benito, que dimana humanidad, no es una excepción pues, incapaz de enfrentarse a los problemas y crecerse ante ellos, pierde el control de sus impulsos y se fuga en dos ocasiones. El fugitivo, aterrorizado, pasadas unas horas, regresa a su refugio. Por fin, a salvo ante una ciudad movilizada en la que:

BEnITo. No han dejado un árbol, Josefina ... ¡Ni uno! ... ¿Te acuerdas de los boulevares? No existen. Todo lo han convertido en grandes y anchas calzadaś, para el transporte de carros de combate... ¡Compadezco a los nacionales, si un día consiguen liberar Madrid y se encuentran con la ciudad así! En una calle muy ancha, hacia la izquierda de la Guindalera, me encontré de frente con una manifestación de obreros. ... Eran miles...Daban vivas a Madrid ... ¡Y todas las banderas eran blancas! ... Debían ser anarquistas, por las cosas tan horribles que decían del enemigo. Las pancartas eran de muerte, de guerra, pidiendo que Madrid tenía que vencer o morir ... (Se vuelve..., 56-57).

Benito, asustado por unas formas de hacer la guerra para las que no está preparado, escucha las razones de Josefina que le llevaron a ocultarle que la guerra había concluido y le perdona por el amor que siente por ella, y que le compensa de todas las penalidades sufridas. A partir de este instante, vuelve los ojos a la realidad y, tras un último paseo por la metrópolis en compañía de un sacerdote, amigo de la familia de Josefina de toda la vida y que los quiere casar a toda costa, cierra la puerta y, feliz, decide continuar el resto de su vida enclaustrado en su hogar, como si de un útero materno se tratara ${ }^{26}$. En este preciso momento, a Benito se le podrían dedicar las mismas palabras que Sancho dirige a don Quijote cuando éste se introduce en la cueva de Montesinos:

SANCHO. Dios te guíe otra vez, y te vuelva libre, sano y sin cautela, a la luz desta vida que dejas por enterrarte en esta escuridad que buscas (Don Quijote..., 1084) ${ }^{27}$.

${ }^{26}$ En su monografía, Erich Fromm, El miedo a la libertad (tít. orig. The Fear of Freedom, trd. Gino Germani, 1942), Barcelona, Paidós, 10. ${ }^{\text {a }}$ edic., 1986, en ap. Libertad $y$ espontaneidad, pp. 246-262, considera que es la vida en sociedad, a pesar de todos sus peligros alienantes, la que permite al ser humano conquistar su verdadera individualidad y libertad.

${ }^{27}$ Miguel de Cervantes, Don Quijote de la Mancha, edic. de Justo García Soriano y Justo García Morales, Madrid, Aguilar, serie Maior, 1990, 2 vols., vol. II, XXII. 
Al espectador todavía le espera otra sorpresa, más asombrosa a nuestro entender, como es el abandono de Benito de su carrera artística. Este hombre, de gran talento, renuncia sin traumas a su prestigio y fama internacionales porque no son el resultado de un esfuerzo consciente:

BENITO: ...Y me da igual, que por mis telas nos den ese dinero o un kilo de garbanzos (Se vuelve..., 74).

...Bengil ha muerto. Entre don Justo [su marchante] y tú inventaros un accidente. Un naufragio, por ejemplo (Se vuelve..., 76).

Es insólito ver a este hombre renunciar, en la mejor etapa de su trayectoria, a todo lo que el resto de los artistas plásticos y literarios sólo es capaz de alcanzar en parte, salvo raras excepciones:

- inspiración constante de temas siempre originales;

- despreocupación por el dinero pues ya ha ganado, durante su reclusión, una importante fortuna;

- aislamiento del entorno social que le permite trabajar en un ambiente tranquilo sin interrupciones por compromisos sociales o laborales.

Sin prever las consecuencias de estas renuncias casi monásticas, Benito se vuelve a encerrar, no se quiere incorporar al mundo del progreso y de las nuevas corrientes culturales. Se recluye en casa a esperar la muerte, satisfecho con vivir de los recuerdos, en un acto de confesada cobardía: «Benito.-Pero ... soy un cobarde ... un cochino cobarde» (Se vuelve..., 55).

Hay aquí un comportamiento reaccionario por parte del personaje que abomina de lo logrado por el hombre: vuelve a la situación primigenia de la contemplación no directa de la verdadera realidad, pues no quiere aceptar que es en ésta donde se debe buscar siempre la verdad y el bien ${ }^{28}$. Convencido de que el individuo es libre antes de entrar a formar parte de la sociedad, como si quisiera poner en práctica la teoría filosófica del solipsismo, prefiere la libertad «en sí y para sí solo», busca la libertad interior, se quiere sentir libre en su propia cárcel. Prefiere la observación de sus propias sombras ya que regresa, de nuevo, al mundo oscuro de los tiempos de la guerra - con el mismo mobiliario y la misma indumentaria- y sus consecuencias.

\section{SEMEJANZAS Y DIFERENCIAS ENTRE LA FICCIÓN LITERARIA Y LA REALI- DAD HISTÓRICA}

Aparte las ya señaladas, observamos, entre el protagonista de la obra de Alonso Millán y los escondidos de los testimonios de la vida real, un

${ }^{28}$ Véase el extenso pasaje en el que Platón, en el diálogo socrático La república, VII, 517 a-c, considera la permanencia en la caverna como un estado antinatural del hombre. 
sentimiento común de preocupación por el desarrollo de los acontecimientos históricos y políticos, en el que ellos se ven involucrados, con la esperanza de que su situación pueda cambiar lo más pronto posible. Comparten, también, una cierta prevención, después de salir a la vida exterior, ante el progreso general, el desarrollo turístico y los cambios sociales que han traído nuevos comportamientos y nuevas formas de vida, contemplados principalmente en la mujer y en la juventud. Manuel Cortés, ex-alcalde de Mijas, en la obra de Ronald Fraser ya citada, opina a este último respecto: - Pero en particular lo que más me ha llamado la atención desde que salí es
la juventud. De eso el turismo tiene parte de culpa ... Son muy indiferentes a
todo lo que no sea divertirse, no hay respeto ni consideración para nadie, ni
para nada. No es que a mí me parezca mal que se diviertan, pero es más
importante aprender antes a conducirse en la sociedad con dignidad y con
vergüenza, y a tener respeto a los semejantes. Todo eso, por lo que he visto,
lo han suprimido (224).

Asimismo, se advierte, tanto en las dos obras de teatro estudiadas como en los testimonios históricos, una gran desconfianza sentida ante los distintos indultos que permitían a los encerrados salir de su escondite, desconfianza que no era en vano puesto que se produjo el fusilamiento de un buen número de escondidos que, precipitadamente, salieron a la luz, según sabemos por los abundantes datos ofrecidos en la obra anteriormente citada de Torbado y Leguineche. Recogemos aquí sólo las palabras de Diego de Noviembre y un poco de yerba: «-Es una trampa. Lo dicen para que salga, para freírme a tiros allá arriba. Me estarán acechando, con los fusiles a la cara ...» (173).

Por último, un hecho que aparece en las dos piezas teatrales analizadas y que difiere totalmente de los testimonios reales, es que los escondidos son cuidados por dos mujeres totalmente extrañas, desconocidas para ellos hasta el momento de su ocultación. En la vida real, la clave del «éxito» de su causa radicó en el apoyo y los desvelos de sus esposas, padres y hermanos que, por ellos, padecieron todo tipo de penalidades y vejámenes, incluida la tortura; estaban todos unidos en el empeño de lograr que la Guardia Civil no encontrara a sus hombres, escondidos en los lugares más inverosímiles ${ }^{29}$.

\footnotetext{
${ }^{29}$ Del mismo modo que en las producciones teatrales de Gala y Alonso Millán, en la novela del aragonés Ramón José Sender, que cuenta con evidentes elementos teatrales, titulada El rey y la reina, publicada por primera vez en 1949, la Duquesa de Arlanza, su protagonista femenina, escondida para evitar caer en 1936 en manos del ejército republicano, tampoco es cuidada por ningún miembro de su familia.
} 


\title{
RESUMEN
}

El tema de los escondidos de la posguerra española en la producción teatral de Antonio Gala y Juan José Alonso Millán, por María Isabel Yagüe Ferrer.

El teatro, expresión de realidades y miserias humanas, aborda el tema de los escondidos, con motivo de la guerra civil española de 1936, en dos obras pertenecientes a dos autores españoles de muy diferente perfil: Noviembre y un poco de yerba, de Antonio Gala, cuyo protagonista, Diego, en el momento de subirse el telón, lleva viviendo en la clandestinidad veintisiete años, y Se vuelve a llevar la guerra larga, de Juan José Alonso Millán, cuyo protagonista, Benito, ha consumido, de la misma forma, treinta y cinco. Ambos, aunque de bandos bélicos contrarios, son víctimas de la guerra en idéntica medida, ya que, tras escapar de la lucha en el frente y lograr esconderse, caen prisioneros de las dos mujeres que les dan cobijo. En una y otra obra, hay un protagonista común: el miedo.

Palabras clave: Antonio Gala, Juan José Alonso Millán, Teatro español contemporáneo, tema del «escondido».

\begin{abstract}
The theatre which expresses reality and human miseries deals with the issue of «people who have had to go into hiding», to mark the occasion of Spanish Civil War of 1936, with two plays written by two very different authors: Antonio Gala's Noviembre y un poco de yerba, whose main character, Diego, when the play begins, has been living in clandestinity for twenty-seven years, and Juan José Alonso Millán's Se vuelve a llevar la guerra larga, whose main character, Benito, has also spent thirty-five years by the same way. But in inspite of belonging to opposing sides, both of them are victims of the war in the same measure, since after escaping from fighting at the front, they become prisoners of the two women who give them shelter. Both plays share a common character: fear.
\end{abstract}

Key words: Antonio Gala, Juan José Alonso Millán, Contemporary spanish theatre, «El escondido» as a theme. 